49. DGP-Kongress, Mannheim

\section{Berufswahl - was raten Sie allergiekranken Jugendlichen?}

\section{Auf Jugendliche entfallen 40\% der als Berufskrankheit anerkannten Hautkrankheiten und ein Drittel der anerkannten allergischen \\ Berufskrankheiten. Dennoch sollte der Allergologe bei entsprechend vorbelasteten Berufsanfängern erst nach genauer Prüfung vom Traumberuf abraten.}

D ie Anzahl jugendlicher Berufsanfänger mit allergischen Erkrankungen oder Asthma hat in den letzten Jahren deutlich zugenommen. Jedoch berücksichtigen die Betroffenen ihr spezielles Risiko bei der Berufswahl nicht, wie die SOLAR-Studie zeigte: $28 \%$ von ihnen gaben einen Berufswunsch mit hohem Asthmarisiko an.

\section{Chancen der Erstuntersuchung nutzen}

Das Jugendarbeitsschutzgesetz (JArbSchG) sieht in $\$ 32$ eine Erstuntersuchung aller minderjährigen Berufsanfänger durch den Hausarzt in den letzten 14 Monaten vor Arbeitsbeginn vor, die mögliche gesundheitliche Risiken erfassen

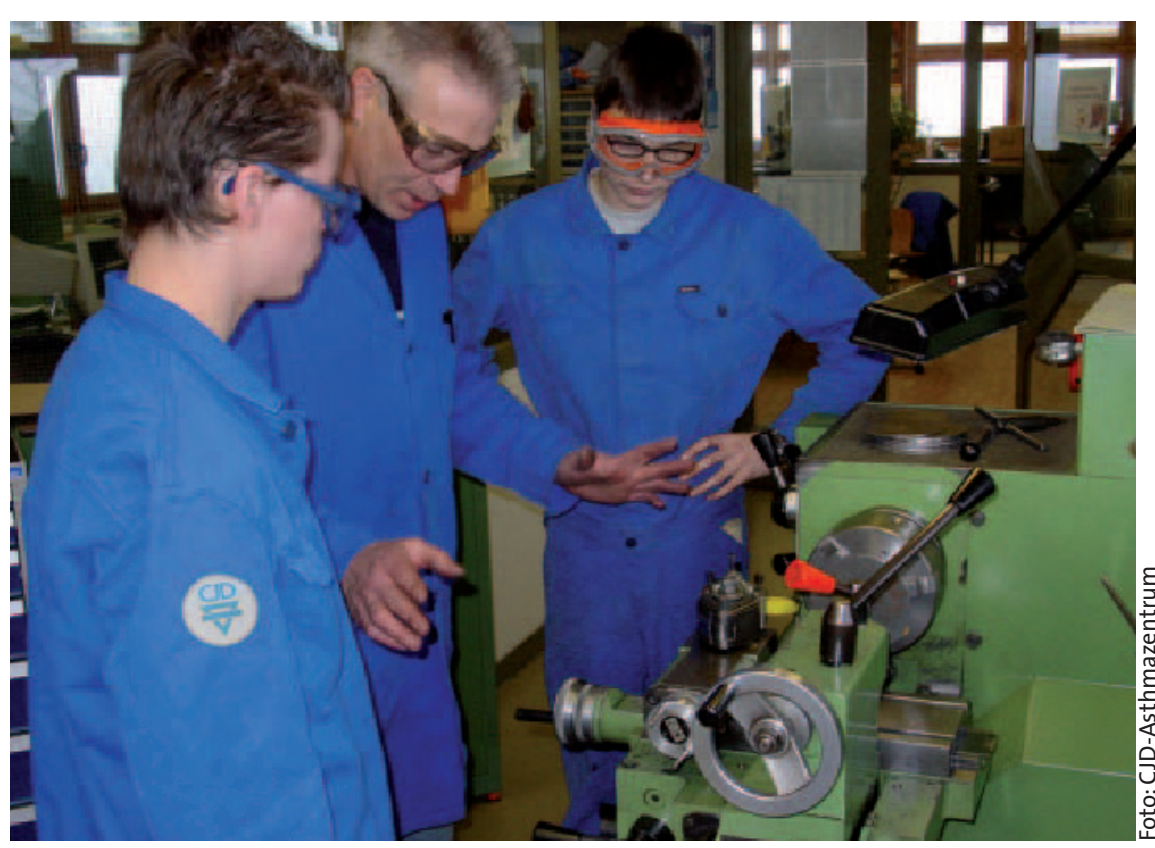

In vielen handwerklichen Berufen kommen Haut und Atemwege mit Allergenen und Irritanzien in Kontakt. soll. Doch in der Praxis würden die Möglichkeiten, die das Gesetz bietet, noch viel zu wenig genutzt, bedauerte Prof. Dr. Dennis Nowak, München. So ist beispielsweise oft nicht bekannt, dass im Rahmen der Erstuntersuchung auch an Fachärzte zur Abklärung überwiesen werden kann. Die exakte Diagnose stelle aber eine wichtige Grundlage für die Beratung der Jugendlichen bei Berufseintritt dar.

Wenn es auch keine evidenzbasierten Empfehlungen für Jugendliche mit Asthma oder Allergien und bestimmten Berufswünschen gibt, hielt Dr. Ulrike Gernhold, München, fest, so zeigten Studien doch klar, dass Atopiker ein erhöhtes Risiko für berufsbedingte allergische Erkrankungen aufweisen. So war beispiels-

\begin{tabular}{|c|c|}
\hline Beruf & Typische Allergene \\
\hline Bäcker & $\begin{array}{l}\text { Mehlstaub, Enzyme } \\
\text { ( } \alpha \text {-Amylase), Hefe }\end{array}$ \\
\hline Bauarbeiter & $\begin{array}{l}\text { Betonhärtemittel, } \\
\text { Metalle im Zement, } \\
\text { Epoxidharze }\end{array}$ \\
\hline Maler, Lackierer & $\begin{array}{l}\text { Kleber, Lacke, Löse- } \\
\text { mittel, Isozyanate, } \\
\text { Epoxidharze }\end{array}$ \\
\hline Friseur & $\begin{array}{l}\text { Haarfarben, Blon- } \\
\text { diermittel, Festiger, } \\
\text { Duftstoffe, Gummi } \\
\text { und Gummihilfsstoffe, } \\
\text { Kosmetika, Nickel }\end{array}$ \\
\hline Pflegebereich & $\begin{array}{l}\text { Naturlatex, Reinigungs- } \\
\text { und Desinfektions- } \\
\text { mittel, Lokalanäs- } \\
\text { thetika, Antibiotika, } \\
\text { Gummihilfsstoffe }\end{array}$ \\
\hline Schreiner & $\begin{array}{l}\text { Holzstäube, Kleber, } \\
\text { Lacke, Lösemittel, } \\
\text { Terpene }\end{array}$ \\
\hline $\begin{array}{l}\text { Tierpfleger, } \\
\text { Landwirt }\end{array}$ & $\begin{array}{l}\text { Tierallergene, Schim- } \\
\text { melpilze }\end{array}$ \\
\hline
\end{tabular}

weise das Risiko für die Entwicklung eines Berufsasthmas bei Bäckerlehrlingen um den Faktor 7,4 erhöht, wenn sie vor Ausbildungsbeginn im Pricktest auf ubiquitäre Allergene reagiert hatten. Und das Rauchen ist eindeutig nicht nur als Risikofaktor für die Asthmaentwicklung allgemein, sondern auch für die Entstehung eines Berufsasthmas belegt.

\section{Nil nocere}

Die individuellen genetischen Faktoren und Umwelteinflüsse können je nach Konstellation zu Allergien führen - oder auch nicht. Daher kann bei einer atopischen Veranlagung nicht von vornherein von bestimmten Berufen abgeraten werden. Für die Beratung der Berufsanfänger gelte daher der Leitsatz „Nil nocere", der Nutzen müsse den Schaden übersteigen, betonte Gernhold. Schließlich hat Arbeit auch positive Effekte: So könnten die Umweltbedingungen am Arbeitsplatz sogar besser sein als zu Hause und der höhere sozioökonomische Status durch die Berufstätigkeit wiege manches Risiko auf. In Zeiten fehlender Ausbildungsplätze stünden zudem gera- 